\title{
Machined abutment screw loosening on external hexagonal-connection implant system: A preliminary in vitro study.
}

BASIC RESEARCH

Félix LF, Medina M, Gómez-Polo C, Ortega R, Del Río Highsmith J, Gómez-Polo M Prosthesis Department. Complutense University of Madrid.

\section{Abstract}

12 Mozo Grau $₫$ were divided into 2 groups of six implants. Each implant assembly was tightened to $20 \mathrm{Ncm}$. A cyclic load was applied to each implant abutment equal to 1 year simulated function.

Reverse torque values (RTV) were lost in each implant assembly when applied a cyclic load.

\section{Background and Aim}

The mechanics of implant screw loosening or fracture are well understood in the field of engineering. Due to the several factors involved, they have not been as widely explored in dentistry. The current knowledge about the role of the implant external hexagon is incomplete. Two of the factors that seem to influence in this complication are the type of connection and the angulation of the implant.

The aim of this preliminary in vitro study was to investigate the effect of abutment screw loosening of an external hexagon implant system when a cyclic loading was applied.

\section{Methods and Materials}

Specimen preparation and testing were performed by the same operator Twelve Mozo Grau Osseous \& (External Hexagonal Connection System) $(3,75 \times 11,5 \mathrm{~mm})$ implants were divided into groups $A$ and $B$.

-Group A: Six $0^{\circ}$ External

Connection Implant Abutments.

-Group B: Six $15^{\circ}$ External

Connection Implant Abutments.

Each implant assembly was tightened using an implant motor (IChiroPro Bien Air $($ ) to $\mathbf{3 0} \mathrm{Ncm}$. All implant

assemblies were placed on a custom made implant fixing jig were a cyclic loading was applied simulating masticatory movement $(300.000$ cycles / 200N / 2Hz) equivalent to 1 year of simulated function. RTVs were recorded before and after loading. Data were analyzed using Wilcoxon signedrank test $(p<, 05)$.

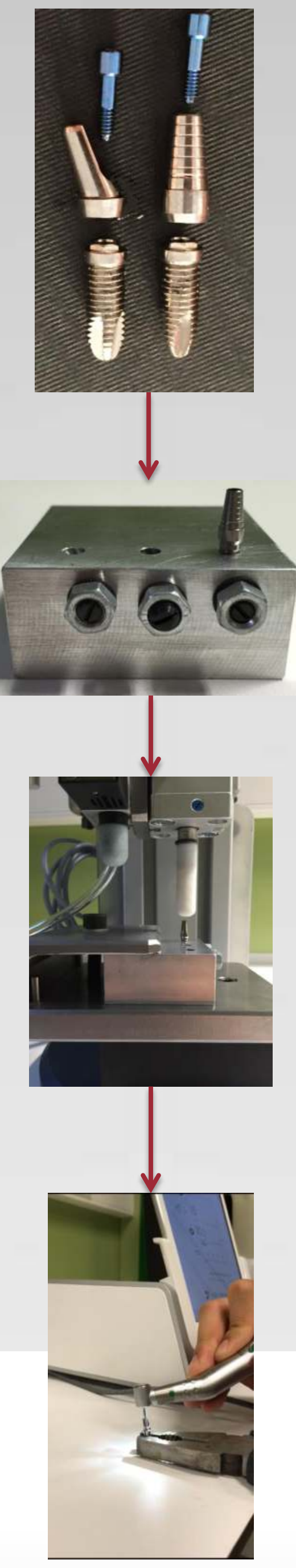

\section{Results}

RTVs were lost in each implant assembly when applied a cyclic load. The average RTV for group A before cyclic load were $(19,1 \pm 2,60)$ and after cyclic load $(15,31$ $\pm 2,11)$. For group $B$ the mean RTV before cyclic load were $(19,55 \pm 1,65)$ and after cyclic load $(12,68 \pm 3,93)$.

Statistically significant differences were obtained when comparing the initial versus final mean RTV of group A $(p<, 046)$ and group $B(p<, 05)$ when exposed to a cyclic load. Likewise, there were also statistically significant differences in the RTV difference values in group $A$ as compared to those of group B $(p<, 003)$.

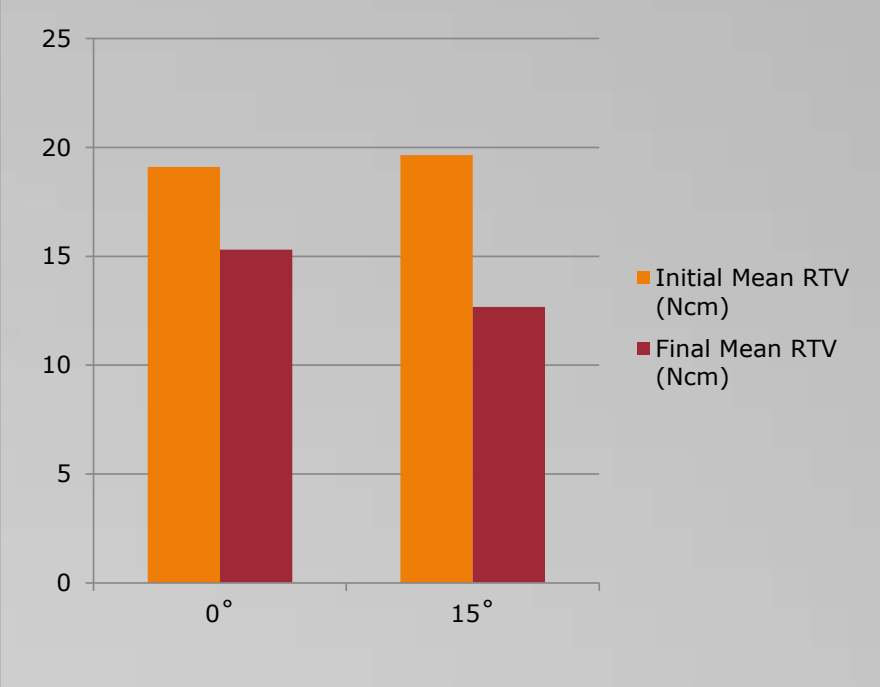

\section{Conclusions}

- Within the limitations of this preliminary in vitro study, it was concluded that:

1. Groups A and B showed decreased RTV after cyclic load of 1 year simulated function.

2. Group $A\left(0^{\circ}\right)$ showed higher RTV than group B (15 ) after cyclic loading which may led us to deduce that angled implant abutments have less stability than straight implant abutments.

\section{References}

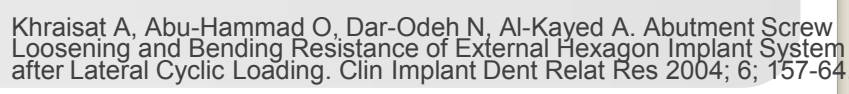

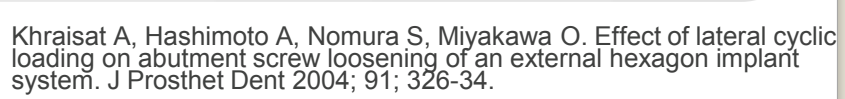

